\title{
Avaliação da Toxicidade de Lixiviados de Aterro Sanitário em Sistema de Lagoas de Estabilização com Testes de Toxicidade Aguda (Daphnia magna)
}

\section{Toxicity Evaluation of Landfill Leachate in Stabilization Ponds by Acute Toxicity}

Tests (Daphnia magna).

\author{
Joel Dias da Silva *
}

Doutor em Engenharia Ambiental pela UFSC. Bolsista do Programa Nacional de Pós-Doutorado - PNPD

MEC/CAPES e MCT/CNPq. Professor do Programa de Pós-Graduaçáo em Engenharia Ambiental da

FURB - Universidade Regional de Blumenau e Instrutor Nível III do SENAI - Blumenau.

\section{Rejane Helena Ribeiro da Costa}

Professora Titular do Departamento de Engenharia Sanitária e Ambiental da UFSC. Pesquisadora Nível IB do CNPq

\section{William Gerson Matias}

Professor Adjunto do Departamento de Engenharia Sanitária e Ambiental da UFSC - Universidade Federal de Santa Catarina.

Armando Borges de Castilhos Jr.

Doutor em Gestáo e Tratamento de Resíduos Sólidos Urbanos. Professor Associado III do Departamento de Engenharia Sanitária e Ambiental da UFSC. Pesquisador Nível II do Conselho Nacional de Desenvolvimento Científico e Tecnológico (CNPq)

*Endereço para correspondência : Rua Araquari, n. 132, Bairro Bela Vista - Săo José (SC), CEP: 88.110-140. E-mail: dias_joel@hotmail.com

Data de Entrada: 19/07/2011

Data de aprovaçăo: 28/03/2012

\section{RESUMO}

Lagoas de estabilizaçáo, em virtude dos seus reduzidos custos de implantaçấo, manutenção e operaçãa, têm-se mostrado uma alternativa viável para o tratamento de lixiviados gerados em aterros sanitários. Desenvolveu-se um sistema experimental composto por três lagoas de estabilizaçáo tratando efluente bruto, em funcionamento desde Março de 2005 até Maio de 2006. Avaliou-se o desempenho do sistema na atenuaçáa do potencial poluidor considerando-se, em especial, fatores como a eficiência de remoçáo carbonácea e de nutrientes nas lagoas, quando submetidas às variaçóes de cargas aplicadas; e o potencial do sistema em detoxificar o efluente tratado. Os resultados mostraram que o sistema de lagoas tratou satisfatoriamente os lixiviados, com eficiências de remoção de 77\% para DQO Total; 94,3\% para amônia. Na avaliaçáo ecotoxicológica do lixiviado, utilizou-se o organismo-teste Daphnia magna Straus, os resultados mostraram-se positivos, atingindo valores desejados de detoxificação do efluente.

Palavras - chave: Aterro Sanitário, Lixiviados, Lagoas de Estabilização.

\section{ABSTRACT}

Stabilization ponds, due to their reduced implementation, maintenance and operational costs, have proved to be a feasible alternative for the treatment of landfill leachate. An experimental system was developed composed of three stabilization ponds treating raw effluent from March 2005 to May 2006. The performance of the system in reducing potential pollution of this effluent was assessed, considering in particular such factors as the carbonaceous removal and the nutrients in the ponds, when submitted to the variations of loads applied; as well as the system's potential to detoxify the effluent treated. Results indicate that the system of ponds treated leachate satisfactorily, with removal efficiency of $77 \%$ for Total COD; $94 \%$ for ammonia. In the ecotoxicologic assessment of the leachate, the organism-test Daphnia magna Straus was used; results were positive, reaching desired levels of detoxification of effluent.

Keywords: Sanitary Landfill, Leachate, Stabilization Ponds. 


\section{INTRODUÇÁO}

Verifica-se no Brasil que a deposição dos resíduos urbanos em aterro sanitário tem sido uma das práticas mais comuns de tratamento destes materiais residuais, em funçāo dos custos reduzidos e disponibilidade razoável de áreas para sua implantação. Entretanto, a técnica de aterro sanitário requer preocupaçóes cotidianas no que se refere às medidas de proteção do ambiente local e seu entorno, uma vez que vários processos bio-fisico-químicos ocorrem simultaneamente, tendo como resultado a geraçáo de dois vetores da poluiçã̃o: os lixiviado e o biogás (CASTILHOS JUNIOR; DALSASSO; ROHERS, 2010; ESCOBAR; LUGO; HWANG, 2009).

A formaçáo de lixiviados ocorre através da passagem da água de chuva através dos resíduos aterrados, resultando no carreamento de compostos orgânicos e inorgânicos solúveis e sua dissoluçáo e suspensáo no líquido, bem como de variados gases (REIS; BIDONE, 2005). Serafim et al. (2003) aponta as dificuldades que as técnicas tradicionais, comumente empregadas para tratamento de efluentes industriais, têm enfrentado para tratamento de lixiviado, incluindo os tradicionais processos biológicos, aeróbio e anaeróbico, como também uma variedade de processos físico-químicos. Como alternativa, a facilidade de construção, operação e manutenção das lagoas de estabilização tornam essa técnica de tratamento bastante apropriada para lixiviados de aterros sanitários (ROCHA et al., 2005; LIMA et al., 2005).

Contudo, observa-se que os sistemas convencionais de tratamento de efluentes não são totalmente capazes de eliminar a ação de substâncias tóxicas. Mesmo com modernos e eficientes tratamentos de efluentes, substâncias xenobióticas, inibidoras, genotóxicas ou não biodegradáveis podem permanecer, causando impactos sobre os ecossistemas, muitas vezes irreversíveis (GOTVAJN; TIŠLER; ZAGORC-KONČAN, 2009;
MARTINS; CASTILHOS JUNIOR; COSTA, 2010) Além disso, os efeitos sinérgicos entre as substâncias também podem ser responsáveis pelo efeito tóxico de um efluente (LAITANO, 2005).

Da mesma forma, o monitoramento destes efluentes de aterro sanitário e seu tratamento exigem a utilizaçáo de uma ampla série de parâmetros físicos e químicos. Porém, nenhum destes parâmetros, isolados ou em conjunto, sáo capazes de determinar os potenciais efeitos tóxicos do efluente na biota aquática. Assim, estimar a toxicidade com base nos resultados de análises físico-químicas é tarefa delicada. Neste sentido, como alternativa complementar á caracterizaçáo física e química de efluentes, recomendase a avaliaçáo toxicológica (GERARDI-GOLDSTEIN et al., 1990; ARAGÂO; ARAUJO, 2006; KNIE; LOPES, 2004; BRENTANO, 2006; LAITANO; MATIAS, 2006; MATIAS et al., 2006). Laitano (2003) acrescenta que, no Brasil, os microcrustáceos, especialmente Daphnia magna, têm sido utilizados como indicadores biológicos em estudos e controle da qualidade da água, e em testes de toxicidade na avaliaçáo de efluentes.

Neste contexto, o presente trabalho busca avaliar a toxicidade dos lixiviados do Aterro Sanitário de Tijuquinhas, em Biguaçú-SC, o qual foi submetido à um tratamento em um sistema em escala piloto de lagoas de estabilização, atentando-se para o risco que substâncias ou compostos químicos tóxicos apresentam para o meio ambiente. Foram avaliados os efeitos agudos, observando-se a letalidade e imobilidade dos organismos-teste Daphnia magna.

\section{METODOLOGIA}

O estudo foi realizado em um sistema formado por três lagoas em série, em escala piloto, para tratamento de lixiviados gerados em aterro sanitário. As lagoas de

Tabela 1. Características Físicas e Operacionais das Lagoas do Sistema Piloto de Tratamento.

\begin{tabular}{|c|c|c|c|}
\hline Dimensóes & $\begin{array}{c}\text { Lagoa } \\
\text { Anaeróbia }\end{array}$ & $\begin{array}{c}\text { Lagoa } \\
\text { Facultativa }\end{array}$ & $\begin{array}{c}\text { Lagoa de } \\
\text { Maturaçáo }\end{array}$ \\
\hline Área - Topo $\left(\mathrm{m}^{2}\right)$ & 0,8 & 1,2 & 1,2 \\
\hline Área - Fundo $\left(\mathrm{m}^{2}\right)$ & 0,8 & 1,1 & 1,1 \\
\hline Profundidade $(\mathrm{m})$ & 1,0 & 1,0 & 1,0 \\
\hline Volume $\left(\mathrm{m}^{3}\right)$ & 0,8 & 1,1 & 1,1 \\
\hline Vazão (L/d) & 60 & 60 & 60 \\
\hline TDH (d) & 13 & 18 & 18 \\
\hline
\end{tabular}


estabilizaçáo foram construídas em formato retangular, com material construtivo à base de fibra de vidro, cujas características físicas e operacionais são apresentadas na Tabela 1.

As instalaçôes foram montadas nas dependências do Laboratório de Efluentes Líquidos e Gasosos - LABEFLU e do Laboratório de Pesquisas em Resíduos Sólidos - LARESO, ambos do Departamento de Engenharia Sanitária e Ambiental da Universidade Federal de Santa Catarina - UFSC, em Florianópolis, Santa Catarina. A Figura 1 apresenta esquematicamente o sistema de tratamento utilizado para os ensaios.

\section{Monitoramento físico-químico do sistema}

Para verificar a possível correlação entre os dados toxicológicos e físico-químicos, bem como monitorar o sistema de lagoas, foram realizadas análises de variáveis de controle de qualidade, como pH, Demanda Química de Oxigênio (DQO) total e Amônia total, observando-se os protocolos do Standard Methods (1998). As amostras foram coletadas, em duplicata, nos seguintes pontos de amostragem: P1: entrada da lagoa anaeróbia, que corresponde à entrada do sistema (efluente bruto); P2: saída da lagoa anaeróbia, que coincide com a entrada da lagoa facultativa; P3: interior da lagoa facultativa, e P4: saída da lagoa de maturação.

\section{Avaliaçáo toxicológica do sistema}

A avaliaçáo toxicológica do lixiviado tratado nas lagoas foi realizada mensalmente através de testes de toxicidade aguda, utilizando com organismo-teste Daphnia magna. $\mathrm{O}$ cultivo dos organismos e os testes foram realizados no Laboratório de Toxicologia Ambiental - LABTOX, observando-se a NBR 12.713 (2004).

Os testes de toxicidade agudos foram realizados expondo os organismos jovens a diferentes concentraçôes da amostra por 48 horas. Baseado na imobilidade dos organismos testados calculou-se a porcentagem de imobilidade por concentração e estimou-se a CE (I) 50 $48 \mathrm{~h}$ - Concentração Efetiva Inicial Mediana. A CE (I) $5048 \mathrm{~h}$ foi calculada através do método estatístico Trimmed Sperman-Karber Method (Hamilton, 1979) para dados náo-paramétricos.

Como os valores numéricos de toxicidade aguda, expressos em CE50 (\%), exprimem uma relaçáo inversa, isto é, quanto menor este valor maior a toxicidade, para o cálculo da eficiência do sistema esses valores sáo transformados em Unidades Tóxicas (UT). Calculada pela Equaçáo 1.

$\mathrm{UT}=100 /$ CE50 (Eq. 1)

Determinaram-se também os valores do FD (Fator de Diluição - a menor diluição da amostra na qual não se observou efeito deletério sobre o organismo teste, sendo efeito deletério imobilidade igual a 10\%).
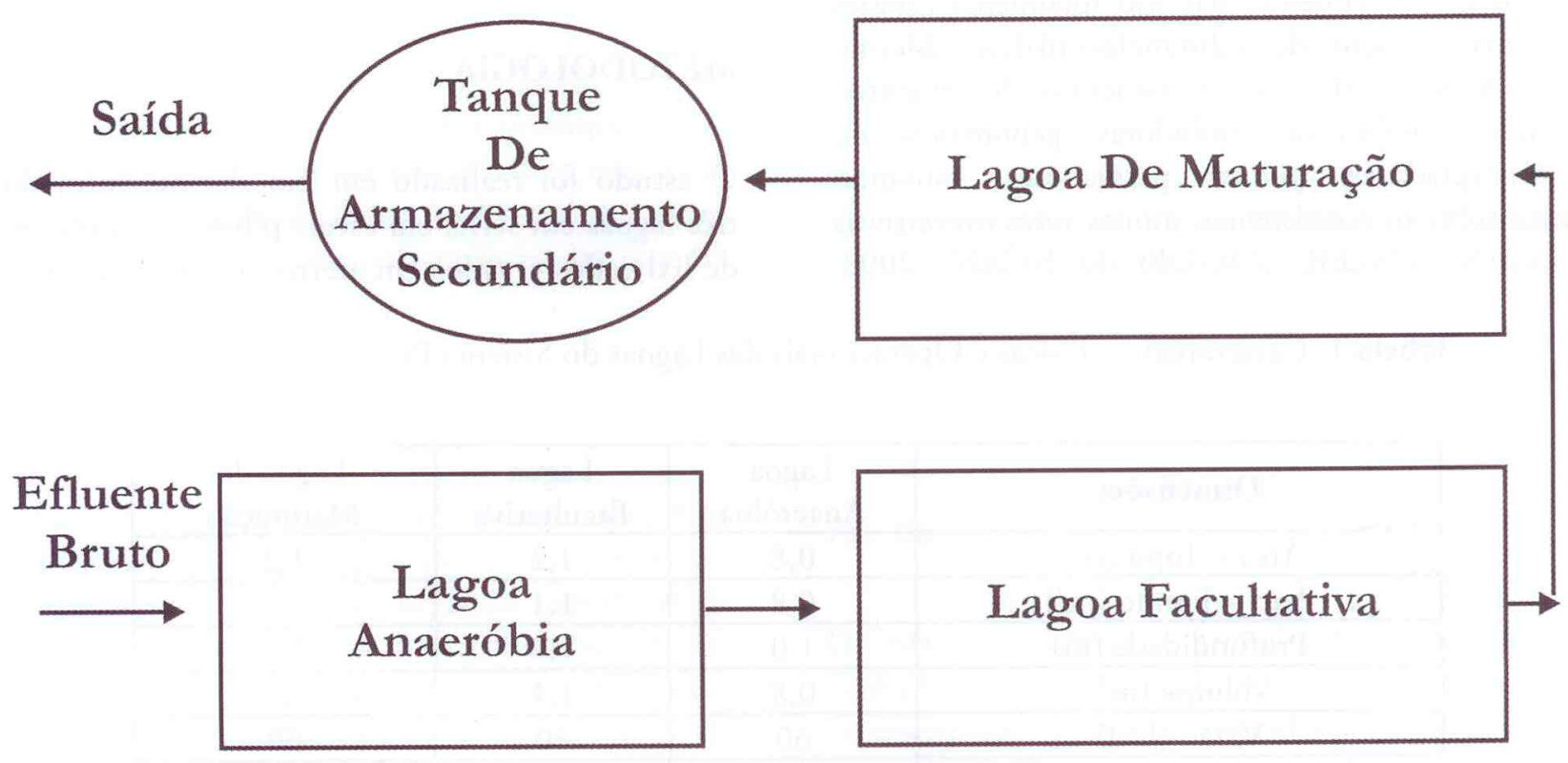

Figura 1 - Esquema das instalaçóes piloto utilizadas no estudo 


\section{RESULTADOS E DISCUSSÃO}

\section{Monitoramento do Sistema de Lagoas}

Os valores médios das cargas aplicadas no sistema em termos de DQO são apresentados na Tabela 2. Para a lagoa anaeróbia, em média, foram aplicados 185,59 $\pm 76,74 \mathrm{gDQO} / \mathrm{m} 3$. dia de carga orgânica volumétrica, enquanto que as cargas orgânicas superficiais aplicadas foram de 105,81 $\pm 44,92 \mathrm{kgDQO} /$ ha.dia e 63,93 $\pm 31,23$ $\mathrm{kgDQO} /$ ha.dia para a lagoa facultativa e de maturação, respectivamente. De modo geral, os índices de remoçấo da carga orgânica para o sistema como um todo, ficaram na faixa de $77 \%$. Estando de acordo com sistemas semelhantes já estudados.

As remoçóes na concentração de amônia foram altas, superiores à $94 \%$ ao se comparar os dados de entrada com o afluente bruto e aqueles da saída da lagoa de maturação, conforme Tabela 3.

O motivo pode estar relacionado ao processo de volatilização, favorecido pelo elevado $\mathrm{pH}$ do afluente bruto e no interior das lagoas ( $>8,5)$, bem como pela assimilaçáo algal nas duas lagoas fotossintéticas (facultativa e maturação). Contudo, não foi observada a nitrificaçấo nessas duas lagoas, embora o ambiente fosse aeróbio, os resultados obtidos para o nitrato foram muito baixos $(<10 \mathrm{mg} / \mathrm{L})$.
Cavalcanti et al. (2001) apud Bastos et al, (2007), indicaram que para que ocorra um desprendimento significativo de amônia, o pH deve ser superior a $8 \mathrm{e}$ que quando a profundidade da lagoa é maior que $1 \mathrm{~m}$, a remoçăo de nitrogênio não ocorre. Pesquisadores como Reed (1985) e Mara et al. (1992), argumentam que num sistema de lagoas de estabilizaçáo, há condicionantes que nāo favorecem a remoçáo do nitrogênio por nitrificação seguida de desnitrificação. Microorganismos nitrificantes exigem suporte físico para o crescimento, como em filtros aeróbios e solo. Outro ponto abordado é que, há a possibilidade de que as algas causem a inibiçāo de bactérias nitrificantes.

Segundo Morais (2005), um efluente que apresenta nitrogênio amoniacal em concentraçốes de 500 a 1000 $\mathrm{mgL}^{-1}$, juntamente com valores de DQO acima de 2000 $\mathrm{mgL}^{-1}$ e alta alcalinidade, é considerado como de difícil tratamento por processo biológico, principalmente devido à alta toxicidade do nitrogênio.

\section{Avaliaçáo Físico-Química do Lixiviado Tratado}

A variável de controle físico-químico que melhor caracteriza uma água residuária é a demanda química de oxigênio (DQO), por identificar o conjunto de substâncias orgânicas e inorgânicas presente em uma amostra. Esta característica possibilita uma comparaçáo, mesmo que limitada, com avaliaçôes toxicológicas (teste de toxidade aguda), que avalia a amostra como

Tabela 2. Cargas Aplicadas de DQO no Sistema de Lagoas de Estabilização.

\begin{tabular}{|c|c|c|c}
\hline Cargas de DQO & $\begin{array}{c}\text { Lagoa Anaeróbia } \\
\left(\mathbf{g D Q O} / \mathbf{m}^{3} \text {.dia }\right)\end{array}$ & $\begin{array}{c}\text { Lagoa Facultativa } \\
(\mathbf{k g D Q O} / \text { ha.dia })\end{array}$ & $\begin{array}{c}\text { Lagoa de Maturação } \\
(\mathrm{kgDQO} / \text { ha.dia })\end{array}$ \\
\hline Aplicada & $185,59 \pm 76,74$ & $105,81 \pm 44,92$ & $63,93 \pm 31,23$ \\
\hline Removida & $42,36 \pm 47,91$ & $41,84 \pm 39,59$ & $32,46 \pm 28,61$ \\
\hline Mínimo & 73,27 & 36,70 & 2,67 \\
\hline Máximo & 451,87 & 252,30 & 140,8 \\
\hline
\end{tabular}

Tabela 3. Cargas Aplicadas de $\mathrm{N}_{-} \mathrm{NH}_{3}$ no Sistema de Lagoas de Estabilização.

\begin{tabular}{|c|c|c|c|}
\hline Cargas de N-NH & $\begin{array}{c}\text { Lagoa Anaeróbia } \\
\left(\mathbf{g ~ N}-\mathbf{N H}^{3} / \mathbf{m}^{3} \text {.dia }\right)\end{array}$ & $\begin{array}{c}\text { Lagoa Facultativa } \\
\left(\mathbf{k g N}-\mathrm{NH}^{3} / \mathbf{h a . d i a}\right)\end{array}$ & $\begin{array}{c}\text { Lagoa de Maturaçáo } \\
\left(\mathrm{kgN}-\mathrm{NH}^{3} / \mathrm{ha} \text {.dia }\right)\end{array}$ \\
\hline Aplicada & $93,40 \pm 31,10$ & $38,70 \pm 26,01$ & $17,10 \pm 13,64$ \\
\hline Removida & $40,10 \pm 28,23$ & $36,20 \pm 26,10$ & $13,2 \pm 12,10$ \\
\hline Mínimo & 40,50 & 4,75 & 0,51 \\
\hline Máximo & 198,90 & 106,52 & 61,58 \\
\hline
\end{tabular}


Tabela 4. Acompanhamento da variável físico-química DQO $\left(\mathrm{mgL}^{-1}\right)$ e cálculo da eficiência do sistema de lagoas. Eficiência do sistema calculada em \%.

\begin{tabular}{|c|c|c|c|c|c|c|c|c|c|c|c|c|c|c|}
\hline \multicolumn{10}{|c|}{ DQO $\left(\mathrm{mgL}^{-1}\right)$ Meses } \\
\hline Amostras estudadas & 1 & 2 & 3 & 4 & 5 & 6 & 7 & 8 & 9 & 10 & 11 & 12 & 13 & 14 \\
\hline Efluente bruto & 2.355 & 6.024 & 4.142 & 2.181 & 2.355 & 2.290 & 2.250 & 1.951 & 1.878 & 1.620 & 1.954 & 2.602 & 2.525 & 2.334 \\
\hline Lagoa anaeróbia & 2.180 & 2.635 & 4.115 & 1.674 & 1.801 & 570 & 1.830 & 1.567 & 1.604 & 1.560 & 1.366 & 2.547 & 1.766 & 1.755 \\
\hline Lagoa facultativa & 121 & 738 & 2.581 & 1.100 & 1.426 & 582 & 1.040 & 1.165 & 1.291 & 1.214 & 1.228 & 2.010 & 1.263 & 1.212 \\
\hline Lagoa de maturação & 30 & 130 & 305 & 216 & 331 & 230 & 498 & 681 & 968 & 887 & 724 & 1.464 & 864 & 579 \\
\hline Eficiência (\%) & 99 & 98 & 92 & 90 & 85 & 90 & 78 & 65 & 48 & 45 & 63 & 44 & 66 & 75 \\
\hline
\end{tabular}

um todo. Por esta razão, uma série de análises da DQO foi realizada no efluente bruto, na lagoa anaeróbia, na lagoa facultativa e na lagoa de maturação para estudar a capacidade das unidades em reduzir a carga de DQO, e verificar se estes resultados têm correlaçáo com os resultados de toxicidade. Estes dados são apresentados na Tabela 4.

A avaliaçáo dos resultados de DQO do efluente bruto permite concluir que os lixiviados de aterro sanitário possuem alta concentraçáo de substâncias orgânicas e inorgânicas Esta mistura complexa pode conter substâncias com atividade química e toxicológica elevada que afeta ecossistemas aquáticos, podendo alterar o equilíbrio ecológico e influenciar na cadeia trófica. Essas oscilações são próprias do efluente em questâo, que é retratado na literatura como efluente de difícil tratamento devido às suas consideráveis oscilaçóes de carga e vazāo, conforme evidenciado nos trabalhos de Santos et al. (2004), Fleck (2003), Hamada; Matsunaga (2000) e Segato; Silva (2000) que também encontraram variaçóes na qualidade e quantidade do efluente durante as suas pesquisas.
Por outro lado verificou-se que o sistema de lagoas foi capaz de reduzir a carga de DQO a 75\%, comparando o efluente bruto com o efluente da lagoa de maturação em termos gerais. Esse percentual de remoçáo foi superior àqueles obtidos com os processos físico-químicos conduzidos por Hamada; Matsunaga (2000), nos quais as melhores remoçốes alcançadas foram de $50 \%$, utilizando concentraçóes elevadas de coagulantes $(>3.000 \mathrm{mgL}-$ 1), com produçáo excessiva de lodo e alto custo operacional. Lange et al. (2006) trataram os lixiviados gerados no Aterro Sanitário de Belo Horizonte/MG com características de aterro sanitário já estabilizado, através de processo oxidativo avançado empregando Reagente de Fenton. Os autores alcançaram remoçóes de DQO superiores a $46 \%$, com média em torno de $61 \%$, sendo a maior remoção alcançada de $75 \%$, ligeiramente mais baixos do que os conseguidos pelo sistema de lagoas de estabilizaçấo em série nesta pesquisa.

\section{Remoçáo da Toxicidade do Lixiviado}

A Tabela 5 apresenta os resultados obtidos nos testes de toxicidade aguda, expondo Daphnia magna por um

Tabela 5. Resultados dos ensaios de toxicidade aguda (CE (I) 50 48h, \%).

\begin{tabular}{|c|c|c|c|c|c|c|c|c|c|c|c|c|c|c|}
\hline \multicolumn{10}{|c|}{ CE (I) $5048 h$} & $\mathbf{\%}$ - Meses \\
\hline Amostras estudadas & 1 & 2 & 3 & 4 & 5 & 6 & 7 & 8 & 9 & 10 & 11 & 12 & 13 & 14 \\
\hline Efluente bruto & 6,2 & 1,6 & 4,3 & 4,3 & 2,9 & 2,4 & 3,8 & 3,9 & 4,2 & 4,1 & 3,8 & 4,4 & 5,4 & 5,4 \\
\hline Lagoa anaeróbia & 6,2 & 3,3 & 1,6 & 4,3 & 4,4 & 4,4 & 8,8 & 4,3 & 5,1 & 4,4 & 4,1 & 35 & 9,5 & 8,5 \\
\hline Lagoa facultativa & 71 & 99 & - & 8,8 & 8,8 & 18 & 35 & 42 & 36 & 55 & 60 & 70 & 17 & 25 \\
\hline Lagoa de maturação & NTA & NTA & - & 11 & 94 & 71 & 68 & 56 & 62 & NTA & NTA & NTA & 48 & 56 \\
\hline
\end{tabular}

$\mathrm{NTA}=$ não apresentou toxicidade aguda 
período de 48 horas a amostras de efluentes líquidos do sistema de lagoas que trata lixiviados de aterro sanitário (resultados expressos em CE (I) 50 48h). Os resultados mostram que os lixiviados estudados têm elevada toxicidade aguda, corroborando com os resultados de Finkler (2002), Machado (2005), Brentano (2006) e Brentano; Matias (2009).

Os testes de toxicidades realizados nas lagoas anaeróbia e facultativa mostram que o efluente destas unidades de tratamento ainda apresentava toxicidade alta a moderada. Por outro lado, os resultados dos testes de toxicidade realizados com amostras da lagoa de maturação, demonstram que as mesmas, na maior parte do período de operação do sistema, nấo apresentaram toxicidade aguda ou apresenta baixa toxicidade aguda. Os cálculos para transformar os valores de CE (I) 50 (\%) em UT estão apresentados na Tabela 6.

O Artigo 24 da Resolução CONAMA 357 (Brasil, 2005) estabelece que, os efluentes de qualquer fonte poluidora somente poderâo ser lançados, direta ou indiretamente, nos corpos de água, após o devido tratamento e desde que obedeçam as condiçôes, padróes e exigências dispostos na mesma. Nesse sentido, o $\$ 1^{\circ}$ do Art. 34, diz que o efluente náo deverá causar ou possuir potencial para causar efeitos tóxicos aos organismos aquáticos no corpo receptor, de acordo com os critérios de toxicidade estabelecidos pelo órgáo ambiental competente.

A Resoluçāo CONAMA 430 (Brasil, 2011) referenda e reforça o estabelecido anteriormente, exigindo avaliação toxicológica para efluentes líquidos disposto no ambiente. Neste sentido o estado de Santa Catarina antecipou-se e estabeleceu os limites máximos de toxicidade aguda para os microcrustáceos, Daphnia magna Straus, de acordo com a Portaria da FATMA No 017 (Santa Catarina, 2002).
Analisando os resultados da Tabela 6, verificou-se que o sistema apresenta eficiência para neutralizar o efeito tóxico de substancias que compốe o lixiviado e que causam toxicidade aguada a Dapnhia magna. Neste sentido, a utilização de sistemas de lagoas para tratar lixiviados de aterros sanitários, será uma boa opçẫo para que seja cumprido o estabelecido na Resoluçáo CONAMA 430 (Brasil, 2011). Os resultados encontraram-se próximos aos de Finkler (2002), Machado (2005), Brentano (2006) e Brentano e Matias (2009), que analisaram o sistema de lagoas de estabilizaçáo tratando o mesmo efluente, mas em escala real.

A presença de uma grande diversidade de substâncias que são comuns no lixiviado proporciona dificuldades para determinar qual a classe de compostos químicos que contribui mais para sua elevada toxicidade. Fatores ambientais, como o $\mathrm{pH}$, também, influenciam no efeito tóxico, principalmente de substâncias/íons cuja espécie tóxica é dependente deste fator, como a amônia. Apesar de náo ter sido apresentado neste trabalho, foi medido o $\mathrm{pH}$ das amostra para controle dos testes de toxicidade.

Os valores de $\mathrm{pH}$ medidos apresentaram incremento durante o período pesquisado, atingindo valores superiores a 8,5 em determinados períodos, o que permite a obtenção da amônia na forma tóxica, ou seja, $\mathrm{NH}^{3+}$ (Fernandes et al., 2006), fato pode ter contribuído para a toxicidade. É evidente que a complexidade química que apresenta os lixiviados de aterros sanitários nâo permite indicar quais as substâncias que contribuem com maior peso no efeito tóxico, pois os efeitos sinergéticos e antagônicos são difíceis de serem identificados.

$\mathrm{Na}$ comparação da eficiência do sistema de lagoas, utilizando a variável de controle UT e a variável de controle DQO, observou-se que, quando se avalia a eficiência (\%) pela variável UT o comportamento do

Tabela 6. Resultados dos ensaios de toxicidade aguda (CE (I) 50 48h, \%).

\begin{tabular}{|c|c|c|c|c|c|c|c|c|c|c|c|c|c|c|}
\hline \multicolumn{10}{|c|}{ UT - Meses } \\
\hline Amostras estudadas & 1 & 2 & 3 & 4 & 5 & 6 & 7 & 8 & 9 & 10 & 11 & 12 & 13 & 14 \\
\hline Efluente bruto & 16,0 & 62,5 & 23,2 & 23,2 & 34,5 & 41,6 & 26,3 & 25,6 & 23,8 & 24,4 & 26,3 & 22,7 & 18,5 & 18,5 \\
\hline Lagoa anaeróbia & 16,0 & 30,0 & 62,5 & 23,2 & 22,7 & 22,7 & 11,3 & 23,2 & 19,6 & 22,7 & 24,4 & 2,9 & 10,2 & 11,7 \\
\hline Lagoa facultativa & 1,4 & 1,00 & - & 11,3 & 11,3 & 5,50 & 2,8 & 2,4 & 2,8 & 1,8 & 1,7 & 1,40 & 5,9 & 4,0 \\
\hline Lagoa de maturaçáo & 1,0 & 1,00 & - & 9,00 & 1,10 & 1,40 & 1,5 & 1,8 & 1,61 & 1,0 & 1,0 & 1,00 & 2,1 & 1,8 \\
\hline Eficiência (\%) & 94,0 & 98,5 & NC & 61,0 & 97,0 & 96,6 & 94,4 & 93,0 & 93,2 & 96,0 & 96,2 & 95,6 & 88,6 & 90,4 \\
\hline
\end{tabular}

$\mathrm{NC}=$ Náo calculado 


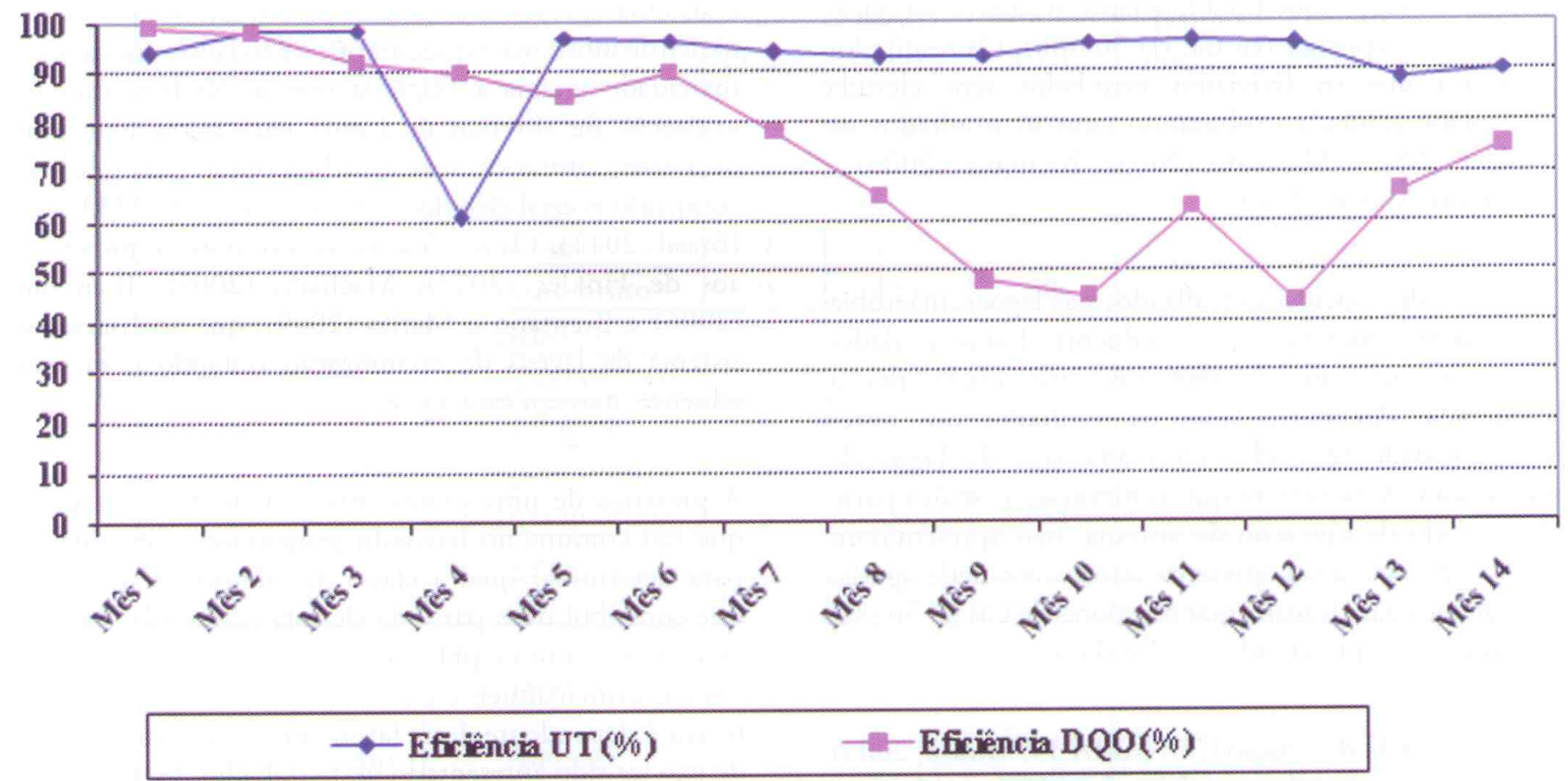

Figura 2. Comparação entre às eficiências do sistema de lagoas, que trata lixiviados de aterro sanitário, utilizando uma variável de controle toxicológico (UT) e uma variável de controle físico-químico (DQO).

sistema é quase que constante e as taxas de redução de toxicidade são elevadas, principalmente após o quinto mês de operação do sistema. No entanto, para a variável de controle DQO, a eficiência (\%) do sistema decai com o tempo, o que pode ser observado na Figura 2. Nos meses dez, onze e doze de operaçáo, as amostras da lagoa de maturaçấo não apresentaram toxicidade aguda, porém as variáveis de controle DQO se encontravam elevadas.

Teoricamente esperava-se uma relação proporcional entre as duas variáveis, fato que não se confirmou. A explicaçáo deste fenômeno pode ser embasada no fato que o sistema foi capaz de degradar substâncias que causaram a toxicidade, porém năo foi eficiente para degradar substâncias que náo causam toxidade aguda, mas contribui para carga de DQO. Neste sentido, os resultados conseguidos em escala piloto mostram que estudos toxicológicos devem ser realizados em conjunto com estudos físico-químicos para possibilitar uma tomada de decisáo mais apropriada na gestâo de resíduos líquidos.

\section{CONCLUSÓES}

Neste trabalho, procurou-se verificar a viabilidade de tratamento de lixiviados gerados em aterros sanitários por meio de um sistema de lagoas de estabilizaçáo em série, consistindo na configuraçấo lagoa anaeróbia + lagoa facultativa + lagoa de maturação. Esta seqüência mostrou-se adequada ao tratamento do efluente bruto, refletidos nos resultados obtidos:

- De modo geral, a eficiência de remoção para o sistema como um todo, ficou na faixa de $75 \% \mathrm{em}$ termos de DQO total, sendo capaz de tratar cargas elevadas, superiores a $400 \mathrm{gDQO} / \mathrm{m} 3$.dia;

- Tratando-se de amônia, o sistema apresentou remoção média de $94 \%$ da concentração afluente de amônia aplicada média de $90 \mathrm{gN}-\mathrm{NH} 3 / \mathrm{m} 3$.dia, resultado do $\mathrm{pH}$ elevado e temperaturas adequadas; 
- Para avaliaçáo ecotoxicológica do lixiviado, embora o afluente apresentasse considerável toxicidade de acordo com estudos prévios, utilizou-se o organismo-teste Daphnia magna Straus, conforme diretrizes da Resolução CONAMA 357/2005 e Portaria No 017/02 da FATMA - SC. Os resultados foram positivos, atingindo valores desejados de detoxificaçáo do efluente. Mesmo com um ligeiro período de sobrecarga, o sistema conseguiu restabelecer-se e de modo gradativo conseguiu remover a toxicidade do efluente.

\section{BIBLIOGRAFIA}

APHA, AWWA, WPCF. Standard Methods for Examination of Water and Wastewater. 20, Ed, 1998.

Aragáo, M. A. e Araujo, R. P. A Métodos de ensaios de toxicidade com organismos aquáticos. Ecotoxicologia Aquática - princípios e aplicaçóes. São Carlos: RIMA, 2006.

Arthur, J. P. Notes On The Design And Operation Of Waste Stabilization Ponds In Warm Climates Of Developing Countries. Technical paper No 7. Washingtown DC: The World Bank. 1983.

ABNT - Associação Brasileira De Normas Técnicas. Ecotoxicologia Aquática - Toxicidade Aguda - Método de Ensaio com Daphnia spp. (Cladocera Crustáceo). NBR 12713. Rio de Janeiro, 17 p., 2004.

Bastos, R. K. X.; Rios, E. N.; Rosa, A. P. Caracterizaçáo E Comportamento de Uma Série de Lagoas de Polimento Tratando Esgotos Sanitários. In: CONGRESSO BRASILEIRO DE ENGENHARIA SANITÁRIA E AMBIENTAL, 24, Belo Horizonte, 2007. Anais... Joinville.: Associação Brasileira de Engenharia Sanitária, 2007.

Brentano, D. M.; Matias, W. G. Determinaçẫo da toxicidade de efluente tratado de aterro sanitário antes e após desinfecçáo por cloração, utilizando Daphnia magna. Química Y Toxicología Ambiental Em America Latina. Buenos Aires: SETAC 2009. 200p, 2009.

Brentano, D. M. Desenvolvimento e Aplicaçấo do Teste de Toxicidade Crônica com Daphnia Magna: Avaliaçấo de Efluentes Tratados de um Aterro Sanitário.
Dissertação (Mestrado em Engenharia Ambiental). Programa de Pós-Graduação em Engenharia Ambiental, Universidade Federal de Santa Catarina, Florianópolis, 2006.

Castilhos Junior, A. B.; Dalsasso, R. L.; Rohers, F. Pré-tratamento de lixiviados de aterros sanitários por filtraçáo direta ascendente e coluna de carváo ativado. Eng. Sanit. Ambient., Rio de Janeiro, v. 15, n. 4, Dec. 2010 . Available from <http://www. scielo.br/scielo.php?script=sci_arttext\&pid=S1413-

$41522010000400011 \& \operatorname{lng}=$ en \& $\mathrm{nrm}=$ iso $>$. access on 10 July 2011. doi: 10.1590/S1413-41522010000400011.

CONAMA - Conselho Nacional do Meio Ambiente. Resoluçẫo N. 357, de 17 de Março de 2005. Dispóe sobre a Classificação dos Corpos de Água e Diretrizes Ambientais para o seu Enquadramento, bem como Estabelece Condiçôes e Padróes de Lançamento de Efluentes e dá Outras Providências. Conselho Nacional do Meio Ambiente. Diário Oficial da Uniâo, Brasília, 17 de Março de 2005.

El-Fadel, M.; Bou-Zeid, E.; Chahine, W.; Alayli, B. Temporal Variation of Leachate Quality Pre-Sorted and Baled Municipal Solid Waste With High Organic And Moisture Content. Waste management, n. 22, p. $269-$ 282. 2002.

Escobar, Z.; Lugo, Y.; Hwang, S. Biochemical Response of Landfill with Manufacturated Aggregates as a Daily Cover. In: WORLD OF COAL ASH (WOCA) CONFERENCE, 2009, Lexington, EUA. <http:// www.flyash.info >. Acesso em: 25 maio 2011.

FATMA - FUNDAÇÃO DO MEIO AMBIENTE DE SANTA CATARINA. Portaria No. 017/02, de 18 de Abril de 2002. Estabelece os Limites Máximos de Toxidade Aguda para Efluentes de Diferentes Origens e dá outras Providências. Disponível em: <<http://labtox.navista. com.br/images/stories/Portaria_017.html > Acesso em: 25 de Setembro de 2007.

Fernandes, F., Costa, R. H. R; Gomes, L. P.; Ferreira, J. A.; Castilhos, A. B. C, Silva, J. D. Tratamento Biológico de Lixiviados de Resíduos Sólidos Urbanos. In: Gerenciamento de Resíduos Sólidos Urbanos com Ênfase na Proteçấo de Corpos D'Água: Prevençáo, Geraçáo e Tratamento de Lixiviados de Aterros Sanitários. Coord.: Armando CASTILHOS Júnior. Projeto PROSAB IV. Rio de Janeiro: ABES, 2006. 
Finkler, R. Avaliação do Efeito Tóxico de Líquidos Lixiviados sobre o Sistema Reprodutivo de Daphnia magna. Dissertação (Mestrado em Engenharia Ambiental). Programa de Pós-Graduaçāo em Engenharia Ambiental, Universidade Federal de Santa Catarina, Florianópolis, 2002.

Fleck, E. Sistema Integrado por Filtro Anaeróbio, Filtro Biológico de Baixa Taxa e Banhado Construído Aplicado ao Tratamento de Lixiviado de Aterro Sanitário. Dissertação (Mestrado em Engenharia). Programa de Pós-Graduação em Engenharia de Recursos Hídricos e Saneamento Ambiental, Instituto de Pesquisas Hidráulicas, Universidade Federal do Rio Grande do Sul, Porto Alegre, 2003.

Gherardi-Goldstein, E. Procedimentos para utilização de testes de toxicidade no controle de efluentes líquidos, CETESB, São Paulo, 1990.

Gherardi-Goldstein, E.; Bertoletti, E.; Zagatto, P. A; Araujo, R. P. A; Ramos, M. L. L. C. Estimativa da Carga Poluidora de Efluentes Industriais da Regiâo de Cubatáo Através de Ensaios Biológicos com Microcrustáceos e Peixes. Anais 13o Congresso Brasileiro de Engenharia Sanitária e Ambiental. ABES, Maceió-AL, p.10. 1985

Giordano, G. Análise e Formulação de Processos para Tratamento dos Chorumes Gerados em Aterros de Resíduos Sólidos Urbanos. Tese (Doutorado em Ciências dos Materiais e Metalurgia). Programa de PósGraduaçáo em Ciências dos Materiais e Metalurgia, Pontifícia Universidade Católica do Rio de Janeiro, Rio de Janeiro, 2003.

Gotvajn, A. Z.; Tišler, T.; Zagorc-Končan, J. Comparison of different treatment strategies for industrial landfill leachate. Journal of Hazardous Material, v. 162, n. 2-3, p. 1446-1456, 2009.

Hamada, J.; Matsunaga, I. Concepçáo do Sistema de Tratamento de Chorume para o Aterro Sanitário de Ilhéus - BA. IX Simpósio Luso-Brasileiro de Engenharia Sanitária e Ambiental. Porto Seguro - BA. p 1515-1524. 2000 .

Jordão, E. P.; Pessôa, C. A. Tratamento de Esgotos Domésticos. 3 ed. Rio de Janeiro: ABES, 720 p. 1995.
Kellner, E.; Pires E. C. Influence of The Thermal Stratification in the Hydraulic Behavior of Stabilization Ponds. In: CONFERÊNCIA LATINO AMERICANA EN LAGUNAS DE ESTABILIZACION Y REUSO, 1., 2000, Santiago de Cali, Colombia. Santiago de Cali, Colombia: [s.n], p.187-198. 2000

Knie, J. L. W.; Lopes, E. W. B. Testes ecotoxicológicos: métodos, técnicas e aplicaçốes. Florianópolis: FATMA/ GTZ, 289 p, 2004.

Laitano, K. S. Determinação do Potencial Tóxico e Genotóxico de Líquido Lixiviado Gerado em Aterramento Sanitário de Resíduos Sólidos Urbanos. Dissertaçâo (Mestrado em Engenharia Ambiental). Programa de Pós-Graduação em Engenharia Ambiental, Universidade Federal de Santa Catarina, Florianópolis, Santa Catarina, 2003.

Laitano, K. S.; Matias, W. G. Testes de Toxicidade com Daphnia magna: Uma Ferramenta para Avaliação de um Reator Experimental UASB. JBSE - J. Braz. Soc. Ecotoxicol. SETAC BRAZIL. v. 1, n. 1, 43-47. 2006.

Lange, L. C.; Alves, J. F.; Amaral, M. C. S.; Melo Júnior, W. R. Tratamento de Lixiviado de Aterro Sanitário por Processo Oxidativo Avançado Empregando Reagente de Fenton. Revista Engenharia Sanitária e Ambiental. Vol. 11, $\mathrm{N}^{\circ}$ 2, Abril - Junho, 2006.

Lima, C. A. A.; Mucha, M. S.; Teles, R. B.; Cunha, R. Estudos Preliminares de Estimativa de Produção Chorume e Avaliaçáo de Alternativas de Tratamento Estudo de Caso: Novo Aterro de Ribeirão Preto - SP. In: CONGRESSO DE ENGENHARIA SANITÁRIA E AMBIENTAL, 23. Campo Grande/MS, 2005. Anais... Campo Grande: Associação Brasileira de Engenharia Sanitária e Ambiental. CD-ROM, 2005.

Mara, D. D.; Pearson, H. Artificial Freshwater Environmental: Waste Stabilization Ponds. In Biotechology, v. 8, p. 177-206, 1986.

Mara, D. D.; Mills, S. W.; Pearson, H. W.; Alabaster, G. P. Waste Stabilization Ponds: A Viable Alternative Small Community Treatment Systems. Journal of the Institution of Water and Environmental Management, v. 6, n. 1. p. 72- 78. London. February, 1992. 
Martins, C. L.; Castilhos Junior, A. B.; Costa, R. H. R. Desempenho de sistema de tratamento de lixiviado de aterro sanitário com recirculação do efluente. Eng. Sanit. Ambient., Rio de Janeiro, v. 15, n. 4, Dec. 2010 . Available from <http://www. scielo.br/scielo.php?script=sci_arttext\&pid $=\$ 1413$ -

$41522010000400013 \& \ln g=e n \& n r m=i s o>$. access on 10 July 2011. doi: 10.1590/S1413-41522010000400013.

Matias, W. G.; Santos Neto, P. M.; Koide, S.; Zanta, V. M.; Castilhos Jr, A. B.; Firta, I. N.; May, M. S. S. Monitoramento da Contaminaçáo Provocada por Lixiviados de Aterros Sanitários. In: Gerenciamento de Resíduos Sólidos Urbanos com Ênfase na Proteçáo de Corpos D'Água: Prevençâo, Geraçấo e Tratamento de Lixiviados de Aterros Sanitários. Coord.: Armando CASTILHOS Júnior. Projeto PROSAB IV. Rio de Janeiro: ABES, 2006.

McGarry, M. G.; Pescod, M. B. Stabilization Pond Design Criteria for Tropical Asia. In: Proceedings of the Second International Symposium on Waste Treatment Lagoons, University of Kansas, Laurence, KS. Ed. R.E. McKinney, p. 114 - 132, 1970.

Moraes, V. A. Caracterização E Estudo de Tratabilidade de Líquidos Lixiviados de Aterros Sanitários. Relatório Técnico. CETESB. São Paulo, 1995.

Paes, R. F. C. Caracterização do Chorume Produzido no Aterro da Muribeca - PE. Dissertaçáo (Mestrado em Engenharia Civil e Ambiental). Programa de PósGraduação em Engenharia Civil, Universidade Federal de Campina Grande, Campina Grande - PB, 2003.

Reed, S. C. Nitrogen Removal in Stabilization Ponds. Journal of the Water Pollution Control Federation, v.
57, n. 1. p. 39- 45. Alexandria. February, 1985.

Reis, M. F. P.; Bidone, F. R. A. Remoçăo de $\mathrm{DBO}_{5}$ e Fósforo do Lixiviado da Compostagem em Sistemas de Banhados Construídos. In: CONGRESSO BRASILEIRO DE ENGENHARIA SANITÁRIA E AMBIENTAL, 23. Campo Grande, 2005. Anais... Campo Grande: Associação Brasileira de Engenharia Sanitária e Ambiental. CD-ROM, 2005.

Rocha, E. M. R.; Motta, M.; Silva, V. L.; Jucá, J. F. T. Estudo do Lixiviado Gerado no Aterro de Muribeca e Tratado pelo Sistema de Lagoas de Estabilizaçáo. In: CONGRESSO BRASILEIRO DE ENGENHARIA SANITÁRIA E AMBIENTAL, 23. Campo Grande, 2005. Anais... Campo Grande: Associação Brasileira de Engenharia Sanitária e Ambiental. CD-ROM, 2005.

Santos, A. F. M. S.; Kato, M. T.; Florencio, L. Estudo Comparativo entre a Biodegradabilidade Aeróbia e Anaeróbia de Chorume de Aterro Controlado. In: XI Simpósio Luso-Brasileiro de Engenharia Sanitária e Ambiental, 2004, Natal RN. Rio de Janeiro: ABES, 2004.

Segato, L. M.; Silva, C. L. Caracterização do Lixiviado do Aterro Sanitário de Bauru. In: Serafim, A. C.; Gussakov, K. C., Silva, F.; Coneglian, C.M. R.; De Brito, N. N.; Sobrinho, G.D.; Tonso S. E Pelegrini, R. Chorume, Impactos Ambientais e Possibilidades de Tratamentos. In: III Fórum de Estudos Contábeis, Faculdades Integradas Claretianas - Rio Claro - SP Brasil, 2003.

Von Sperling, M. Princípios Básicos do Tratamento de Esgotos: Princípios de Tratamento Biológico de Águas Residuárias. [s.1.]: DESA - UFMG, 210p. 1996. 